\title{
Spatial variations of shallow and deep soil moisture in the semi-arid Loess Plateau, China
}

\author{
L. Yang ${ }^{1}$, W. Wei ${ }^{1}$, L. Chen ${ }^{1}$, F. Jia ${ }^{1}$, and B. Mo ${ }^{2}$ \\ ${ }^{1}$ State Key Laboratory of Urban and Regional Ecology, Research Center for Eco-Environmental Sciences, \\ Chinese Academy of Sciences, Beijing, 100085, China \\ ${ }^{2}$ Gansu Academy of Forestry Sciences, Lanzhou, 730000, China \\ Correspondence to: W. Wei (weiwei@ rcees.ac.cn)
}

Received: 27 March 2012 - Published in Hydrol. Earth Syst. Sci. Discuss.: 5 April 2012

Revised: 18 August 2012 - Accepted: 20 August 2012 - Published: 10 September 2012

\begin{abstract}
Soil moisture in deep soil layers is an important relatively stable water resource for vegetation growth in the semi-arid Loess Plateau of China. Characterizing the spatial variations of deep soil moisture with respect to the topographic conditions has significant importance for vegetation restoration. In this study, we focused on analyzing the spatial variations and factors influencing soil moisture content (SMC) in shallow $(0-2 \mathrm{~m})$ and deep $(2-8 \mathrm{~m})$ soil layers, based on soil moisture observations in the Longtan watershed, Dingxi, Gansu province. The vegetation type of each sampling site for each comparison is same and varies by different positions, gradients, or aspects. The following discoveries were captured: (1) in comparison with shallow SMC, slope position and slope aspect may affect shallow soil moisture more than deep layers, while slope gradient affects both shallow and deep soil moisture significantly. This indicates that a great difference in deep soil hydrological processes between shallow and deep soil moisture remains that can be attributed to the introduced vegetation and topography. (2) A clear negative relationship exists between vegetation growth condition and deep soil moisture, which indicates that plants under different growing conditions may differ in consuming soil moisture, thus causing higher spatial variations in deep soil moisture. (3) The dynamic role of slope position and slope aspect on deep soil moisture has been changed due to large-scale plantation in semi-arid environment. Consequently, vegetation growth conditions and slope gradients may become the key factors dominating the spatial variations in deep soil moisture.
\end{abstract}

\section{Introduction}

In the semi-arid Loess Plateau of China, soil moisture is an important water source for plant growth in local ecosystems (Cao et al., 2009). This region is covered by nearly $100 \mathrm{~m}$ loess in thickness and a loose soil structure (Chen et al., 2007b), and the groundwater levels in this region are generally at depths of $30 \mathrm{~m}$ to $100 \mathrm{~m}$ below surface (Mu et al., 2003). Little of the groundwater at these depths can be used as a supply for soil evaporation and plant transpiration. For this reason, plants in this area are forced to develop deep and robust root systems to utilize soil moisture stored in the deep soil layers (Chen et al., 2008a). Therefore, deep soil moisture (usually $2 \mathrm{~m}$ below surface) becomes especially important for the sustainable growth of plants in this area (Chen et al., 2008a; Y. Wang et al., 2011).

In order to control serious soil erosion in the Loess Plateau, large-scale implementation of the "Grain to Green Program" (GTGP, also known as the Sloping Land Conversion Program or the Farm to Forest Program) was initiated by the central government in recent years (Chen et al., 2010; Liu et al., 2008). Non-native species were used to restore local degraded ecosystems, and introduced vegetation became the main vegetation type in this region (Wang et al., 2007). However, introduced vegetation usually needs more soil moisture than native plants and can rapidly deplete limited soil moisture stored in deep soil layers (Wang et al., 2009, 2010b). For this reason, large-scale system restoration using introduced vegetation may be limited by soil water availabilities (Chen et al., 2010), and may have negative impacts on the sustainability of the restoration effort (W. Liu et al., 2010), 
watershed hydrological processes (Yang et al., 2008), and ecosystem services (Chazdon, 2008; Liu et al., 2008).

Several recent studies have been conducted on deep soil moisture depletion influenced by large-scale vegetation restoration in the Loess Plateau. For instance, soil moisture consumption rates were found to depend on vegetation types (Wang et al., 2009, 2010b). It is also found that vegetation species markedly influence the balance of deep soil moisture (L. Wang et al., 2011). W. Liu et al. (2010) found a negative relationship between deep soil moisture content and the age of the plants. However, limited attention has been given to the question of how spatial variation in deep soil moisture is affected by environmental factors due to the arduous work required. As spatial variations of soil moisture have important implications on agriculture (Hebrard et al., 2006; Y. Liu et al., 2010), soil erosion (Chen et al., 2007b; Fitzjohn et al., 1998) and vegetation restoration (Engelbrecht et al., 2007), understanding its dynamic role will provide a scientific basis for the optimization of spatial allocation in the vegetation restoration efforts. Specifically, because deep soil moisture is an important stable water source for introduced vegetation in the semi-arid Loess Plateau, understanding the spatial variation of deep soil moisture is fundamental for the possible optimization of vegetation restoration.

In fact, dozens of factors may impact deep soil moisture. Besides vegetation, upslope contributing areas, topographical factors, geographical location, land use, and soil types all play key roles (Favreau et al., 2009; Fu et al., 2003; GómezPlaza et al., 2000; Qiu et al., 2003; Wang et al., 2010a; Shi et al., 2012). Specifically, the detailed topographic variability as represented by the complex hills and gullies in the Loess Plateau results in significant local redistribution of precipitation, solar radiation and surface runoff (Qiu et al., 2010; Zhu and Shao, 2008). This redistribution inevitably affects the spatial variations of soil moisture (Legates et al., 2011; Meerveld and McDonnell, 2006; Vivoni et al., 2008). Because soil properties in the Loess Plateau are homogeneous (Yang and Tian, 2004), the vegetation and topography are key factors contributing to soil moisture dynamics in the semiarid loess hilly region (Qiu et al., 2001).

Based on the above discussion, soil moisture is significantly influenced by topography in such regions. However, there are two questions that remain unresolved. Firstly, does the topographic variability affect soil moisture in deep layers? Secondly, how do dynamics in deep soil moisture respond to the introduced vegetation restoration? Both questions need clear answers urgently, which can provide a better understanding of soil moisture dynamic between shallow and deep soil layers and provide scientific basis for the optimization of vegetation restoration efforts, especially for the semiarid regions. Therefore, the objectives of this study are (1) to analyze the spatial variation of shallow and deep soil moisture under different topographic factors, (2) to investigate whether the deep soil hydrological processes are the same as in the shallow soil under the influence of topography, and
(3) to elucidate the main factor affecting the spatial variation in deep soil moisture.

\section{Materials and methods}

\subsection{Study area}

Longtan watershed $\left(35^{\circ} 43^{\prime}-35^{\circ} 46^{\prime} \mathrm{N}, 104^{\circ} 27^{\prime}-104^{\circ} 31^{\prime} \mathrm{E}\right)$, which is located in Dingxi, Gansu province, covers an area of about $16.1 \mathrm{~km}^{2}$ and ranges from $1840 \mathrm{~m}$ to $2260 \mathrm{~m}$ a.s.l. (above sea level) with a highly fragmented landscape. It belongs to a typical semi-arid loess hilly region, with approximately $6.8^{\circ} \mathrm{C}$ mean annual temperature and $386 \mathrm{~mm}$ mean annual rainfall. Most rainfall occurs in the form of thunderstorms during the summer months from July to September. The potential annual evaporation (pan evaporation) is about $1649 \mathrm{~mm}$. All meteorological data were provided by the meteorological station $0.6 \mathrm{~km}$ from the watershed and represent 45-yr averages (1961-2006). The rainfall had a uniform distribution in the watershed based on five spatial-distributed auto-recording rain gauges during 20082010. Soil types in this study area are mainly composed of loess soil with low fertility, and vulnerable to soil erosion. Such kind of soil has a loose structure, low soil moisture field capacity $\left(0.180-0.240 \mathrm{~g} \mathrm{~g}^{-1}\right)$ and low organic matter content (ca. 0.2-2.9\%). The wilting point in the study area is $0.054 \mathrm{~g} \mathrm{~g}^{-1}$ (Chen et al., 2007a). Soil thickness varies from 40 to $60 \mathrm{~m}$.

The predominant land use types are sparse native grassland and rainfed farmland, and then pasture grassland, shrubland, and forestland. The native vegetation in study area is sparse grass, dominated by species bunge needlegrass (Stipa bungeana Trin.), common Leymus (Leymus secalinus (Georgi) Tzvel.), Altai heteropappus (Heteropappus altaicus (Willd.) Novopokr.), etc. The introduced vegetation types are alfalfa (Medicago Sativa), korshinsk peashrub (Caragana korshinskii), Siberian apricot (Armeniaca sibirica (L.) Lam.), Chinese red pine (Pinus tabulaeformis Carr.), and others. Located in the semi-arid climatic zone, water shortage is the major constraint to vegetation growth and agriculture production in this area.

\subsection{Observation and analysis}

\subsubsection{Experimental site design}

Based on vegetation distribution characteristics in study area, the native natural grassland, farmland and planted vegetation lands were conducted for analysis. Furthermore, five typical introduced vegetation types were selected: alfalfa (M. sativa), korshinsk peashrub (C. korshinskii), Chinese arborvitae (Platycladus orientalis), Chinese red pine (P. tabulaeformis) and Siberian apricot (A. sibirica). 
Native grassland: The native grassland is the dominant native species community in this region. The main species are native low water-demanding grasses and herbs, including common Leymus ( $L$. secalinus), bunge needlegrass (S. bungeana), Altai heteropappus (H. altaicus), Mongolian thyme (Thymus mongolicus Ronn.), and others. According to local farmers and stakeholders, natural grasslands have been kept from human disturbance for at least $50 \mathrm{yr}$.

Farmland: Crops were planted annually in farmlands. From 2009 to 2010, potatoes were sown in April and harvested manually at the end of September or the beginning of October in farmland sites. Abandoned farmland is fallowed with native grasses and herbs to grow since 2002 . The soil moisture conditions in farmland could be considered as the reference condition before introduced vegetation was planted.

Introduced vegetation lands: The lands with introduced vegetation were converted from farmland where in pasture grasslands (planted with alfalfa), shrubs (planted with korshinsk peashrub) and forests (planted with Chinese arborvitae, Chinese red pine and Siberian apricot) were involved. Alfalfa was planted in 2003 after "Grain-to-Green" project was initiated. In rainfall-deficit years, alfalfa was cut only once because of its poor growth, while it was cut twice in rainfall-rich years. The korshinsk peashrubs were planted in 1984. The Chinese arborvitae, Chinese red pine and Siberian apricot were planted with same density in 1980, 1972 and 1960, respectively.

In this study, experimental sites were divided into three groups to study the spatial variation of shallow and deep SMC under the influence of topographical factors. (1) Eight typical transects with different vegetation covers (NG - native grassland, $\mathrm{PO}$ - potato farmland, $\mathrm{AF}$ - abandoned farmland, $\mathrm{AL}$ - alfalfa grassland, $\mathrm{KP}$ - korshinsk peashrub, $\mathrm{CP}$ - Chinese red pine, CA - Chinese arborvitae, and SA Siberian apricot) were selected to compare soil moisture variations on different positions. The transects were selected based on upslope contributing areas and flow direction. All transects were covered with same vegetation from top to the bottom of the hillside, along with the flow direction and upslope contributing areas. There were three separate sampling sites in each transect on the upper, middle and downhill slopes. Each transect had same slope aspect and similar slope gradient. (2) To elucidate the dynamic role of slope aspect on shallow SMC and deep SMC, six groups of NG, PO, $\mathrm{AF}, \mathrm{AL}, \mathrm{KP} 1, \mathrm{KP} 2$ on different slope aspects were selected to compare SMC affected by slope aspects. Each site selected in the same group was on same slope position, same slope gradient and same vegetation growth conditions, but varied by slope aspects. (3) Slope gradient was particularly highlighted in this study. Four groups of NG, AL, CP, and CA forestland in different slope gradients were selected to compare SMC affected by slope gradient. Each site in a group was on the same slope position and aspect, but varied by slope gradients. From the limited vegetation distribution characteristics in the study area, not all the eight different types of vegetation can be found in different slope aspect or gradient. Soil moisture data of some sampling sites were simultaneously used in Group 1, Group 2 or Group 3. For example, the site "PO-U" and "PO-Sunny" are the same sampling site, and the site "KP-M" and "KP1-Sunny" are also the same sampling site (Fig. 1).

\subsubsection{Shallow and deep SMC measurement}

Soil moisture measurements in the growing seasons were made biweekly (beginning and middle of each month) for the $2-\mathrm{m}$ profile in 20-cm increments, from April to October in 2009 and 2010. Soil samples were taken by a drill and stored in sealed aluminum cases when taken out. Then the sealed aluminum cases were taken to laboratory to measure SMC (unit: $\mathrm{g}^{-1}$ ) by using gravimetric approach. The SMC was determined using the oven-dry method $\left(24 \mathrm{~h}\right.$ at $\left.105^{\circ} \mathrm{C}\right)$. At each sampling time, three sampling profiles were randomly chosen to obtain the average SMC each time at each experimental site. In this study, 26 times in total shallow SMC data were collected. The depth-averaged SMC of each experimental site at each measuring time was calculated by Eq. (1):

$\mathrm{SMC}_{j}=\frac{1}{i} \sum_{i=1}^{i} \mathrm{SMC}_{i}$

where $i$ is the number of measurement layers at the site $j$, and $\mathrm{SMC}_{i}$ is the mean soil moisture content in layer $i$ calculated by three random sampling profiles. The number of measurement layers of shallow SMC is 10 .

The temporal-averaged shallow SMC of each experimental site was calculated by Eq. (2):

$\mathrm{SMC}_{n}=\frac{1}{n} \sum_{n=1}^{n} \mathrm{SMC}_{j}$

where $n$ is the number of measurement times at the site $j$. The number of measurement times of shallow SMC is 26.

In August 2010, deep SMC in the 2-8 m layers was measured at each site. Soil samples in the depth of 2-8 $\mathrm{m}$ were taken by a drill $(5 \mathrm{~cm}$ in diameter). The soil samples were sealed in airtight aluminum cylinders and brought to the laboratory for determination of gravimetrically SMC (unit: $\mathrm{g} \mathrm{g}^{-1}$ ). A total of 30 soil samples were collected from each sampling point. Three sampling profiles were randomly chosen to obtain the average SMC each time at each experimental site. The depth-averaged deep SMC of each experimental site at each measuring time was calculated by Eq. (1), and the number of measurement layers of deep SMC is 30 .

\subsubsection{Soil properties and vegetation characteristics}

The latitude, longitude and elevation were determined for each experimental site using a Garmin GPS60. Site slopes and aspects were determined by using compass method in 


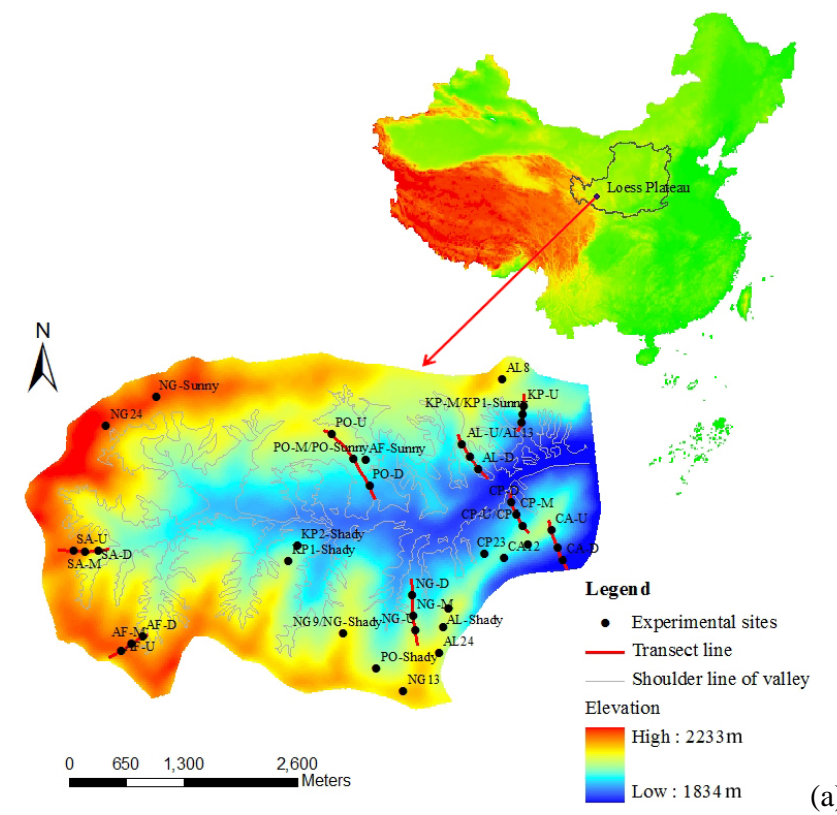

(a)
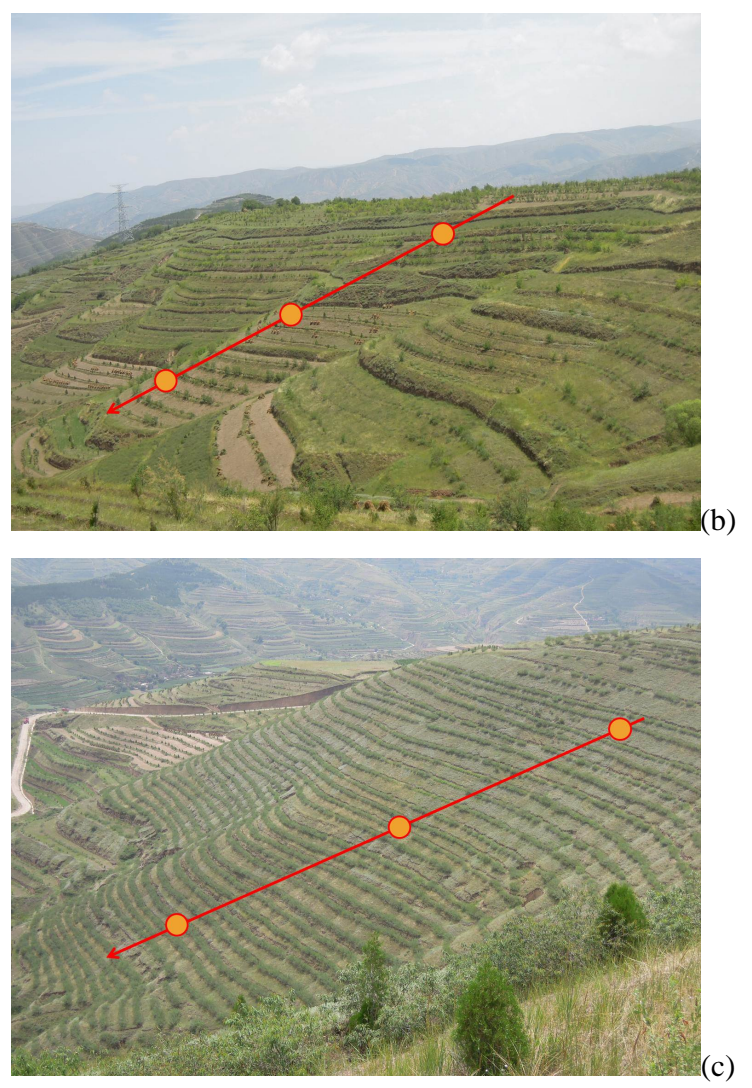

Fig. 1. Location of the study area and experimental sites. (a) Location of the study area in the Loess Plateau and experimental sites in watershed; (b) photo of alfalfa grassland transect (land converted from farmland and planted with alfalfa); (c) photo of korshinsk peashrub shrubland transect (land converted from farmland and planted with korshinsk peashrub). Note: NG represents native grassland; PO represents farmland planted with potato; AF represents abandoned farmland; AL represents alfalfa; KP represents korshinsk peashrub; CP represents Chinese red pine; CA represents Chinese arborvitae; SA represents Siberian apricot. field investigation. Slope gradient was recorded in degrees. Slope aspect (clockwise from north), which is a circular variable, was transformed into cos(aspect). At each site, undisturbed soil cores were collected for soil bulk density measurement in surface $(0-5 \mathrm{~cm})$ and subsurface soil layers $(20$ $25 \mathrm{~cm}$ ) in metal cylinders (diameter $5 \mathrm{~cm}$, length $5 \mathrm{~cm}$ ). Soil bulk density and porosity were determined from the volumemass relationship for each core sample. Disturbed soil samples were collected to a depth of $1 \mathrm{~m}$ at $0.2 \mathrm{~m}$ intervals using a soil auger for each sampling point. Soil particle sizes were evaluated using the Mastersizer 2000 apparatus manufactured by Malvern. The proportions of clay $(<0.002 \mathrm{~mm})$, silt $(0.002-0.02 \mathrm{~mm})$, and sand $(>0.02 \mathrm{~mm})$ contents were then calculated. Soil organic matter (SOM) content was determined by the dichromate oxidation method.

At each experimental site, vegetation investigation was also conducted. At forest sites, the stand density (plants/ha), tree height $(\mathrm{m})$, diameter at the breast height $(\mathrm{DBH}, \mathrm{cm})$, canopy width in a $10 \mathrm{~m} \times 10 \mathrm{~m}$ quadrat, and the total canopy or coverage of each quadrat were recorded, respectively. At shrub sites, plant height $(\mathrm{m})$ and canopy width in a $10 \mathrm{~m} \times 10 \mathrm{~m}$ quadrat were measured, and canopy cover was measured by visual estimation. Species composition, total herbaceous coverage, plant height, and biomass were measured in each herbaceous quadrat (Table 1).

\subsection{Statistical methods}

The basic statistical features of mean values (Mean) and standard deviation (S.D.) were analyzed and reported for each site. One-way ANOVA was used to assess the contribution of different topography factors to the overall variation of soil moisture variable. Multiple comparisons were made using the least significant difference (LSD) method. To identify the relationships between SMC and environmental factors such as geographical, and vegetation variables, a correlation analysis was conducted. SPSS ${ }^{\circledR}$ (Version 18.0) was used for all of the statistical analyses. Canonical correspondence analysis (CCA), a constrained ordination technique, was used to identify specific environmental variables at different depths. CCA was performed using the program CANOCO version 4.5. The following environmental variables, which showed significant correlations with SMC, were included in the CCA: vegetation type, slope position, slope aspect, and slope gradient.

\section{Results}

\subsection{Spatial variations of SMC on different slope positions}

No significant difference in SMC was found between different slope positions in shallow layers, and the vegetation covers did not matter (Table 2). The SMC in alfalfa transect increased from top to foot of the hillside. Interestingly, the 


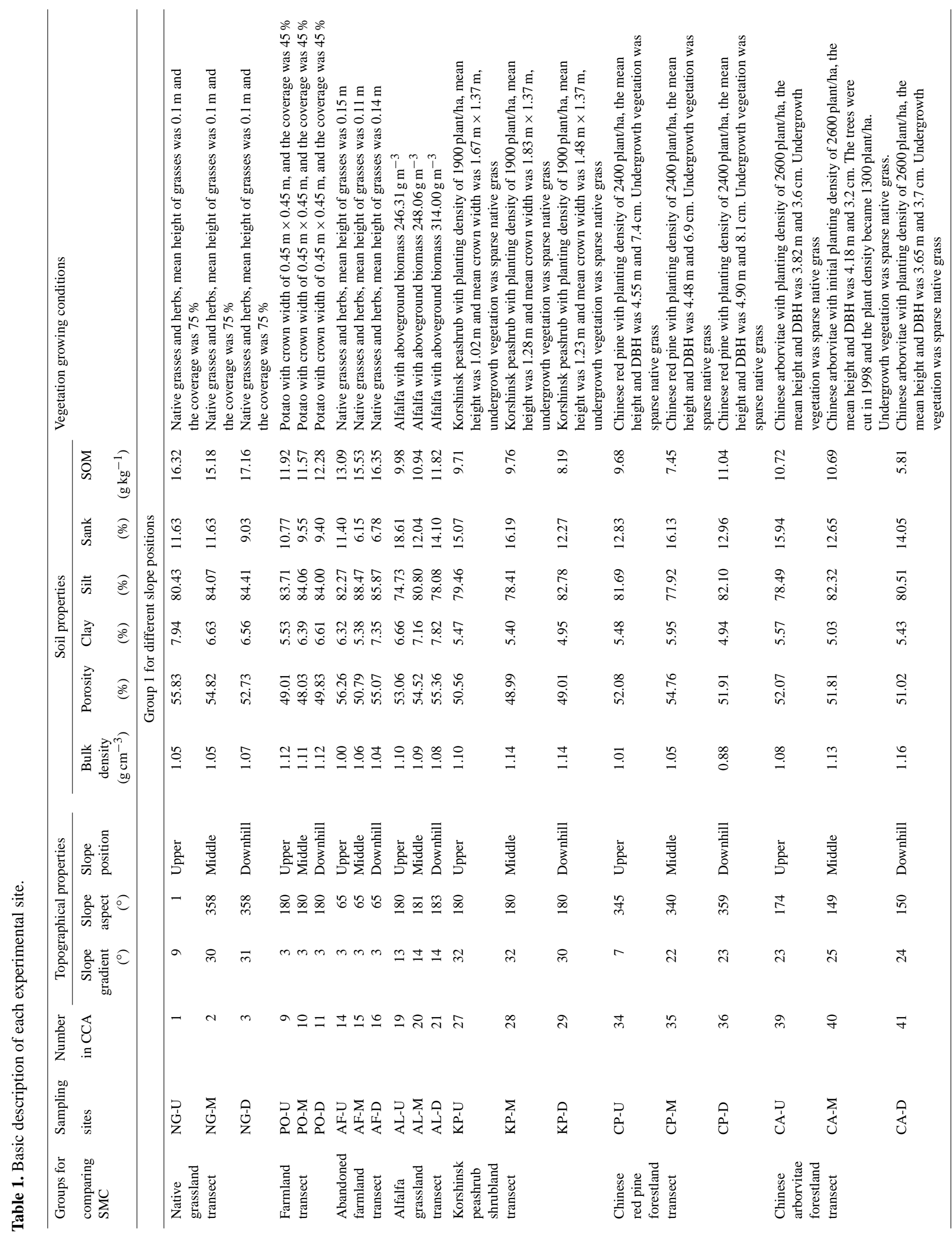




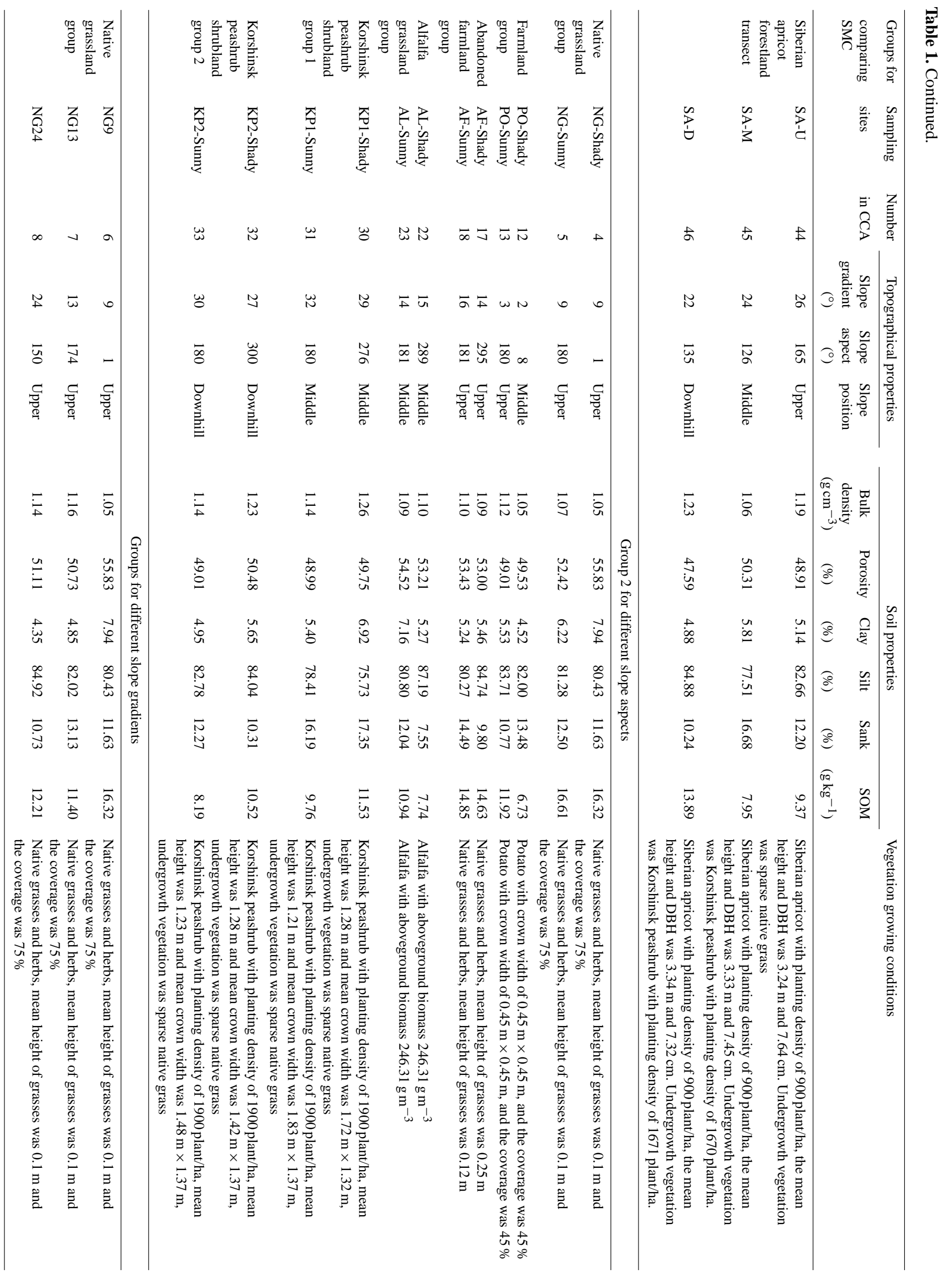




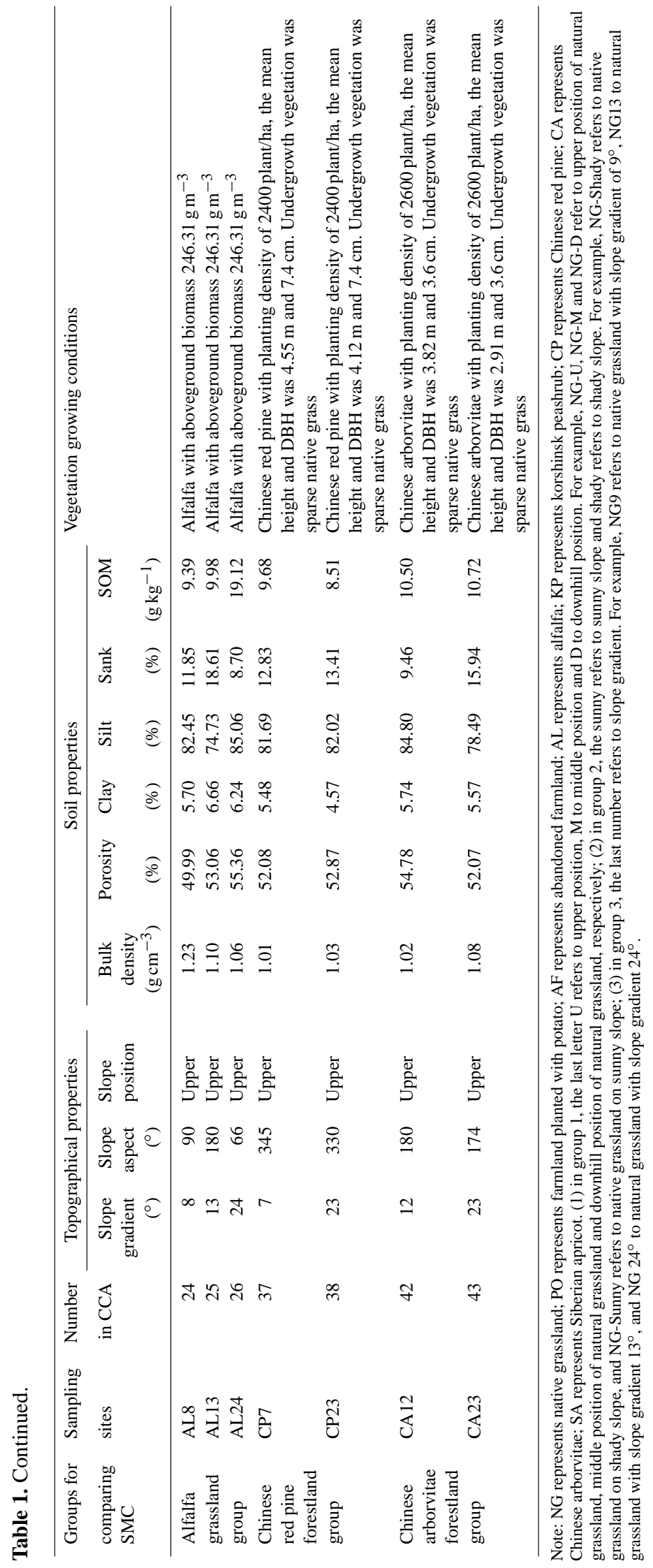




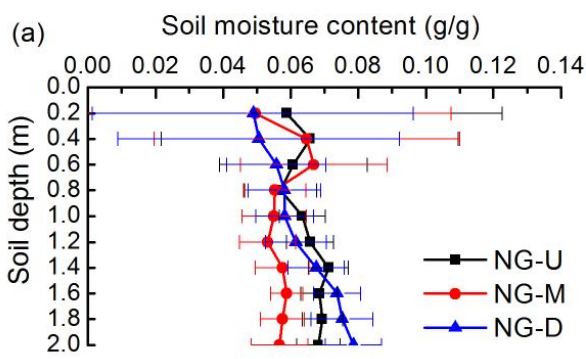

(b) Soil moisture content $(\mathrm{g} / \mathrm{g})$

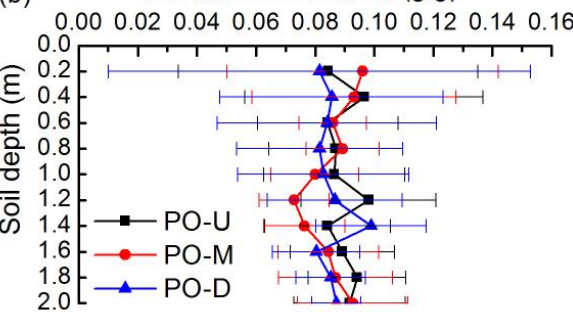

(c) Soil moisture content $(\mathrm{g} / \mathrm{g})$

(d) Soil moisture content $(\mathrm{g} / \mathrm{g})$
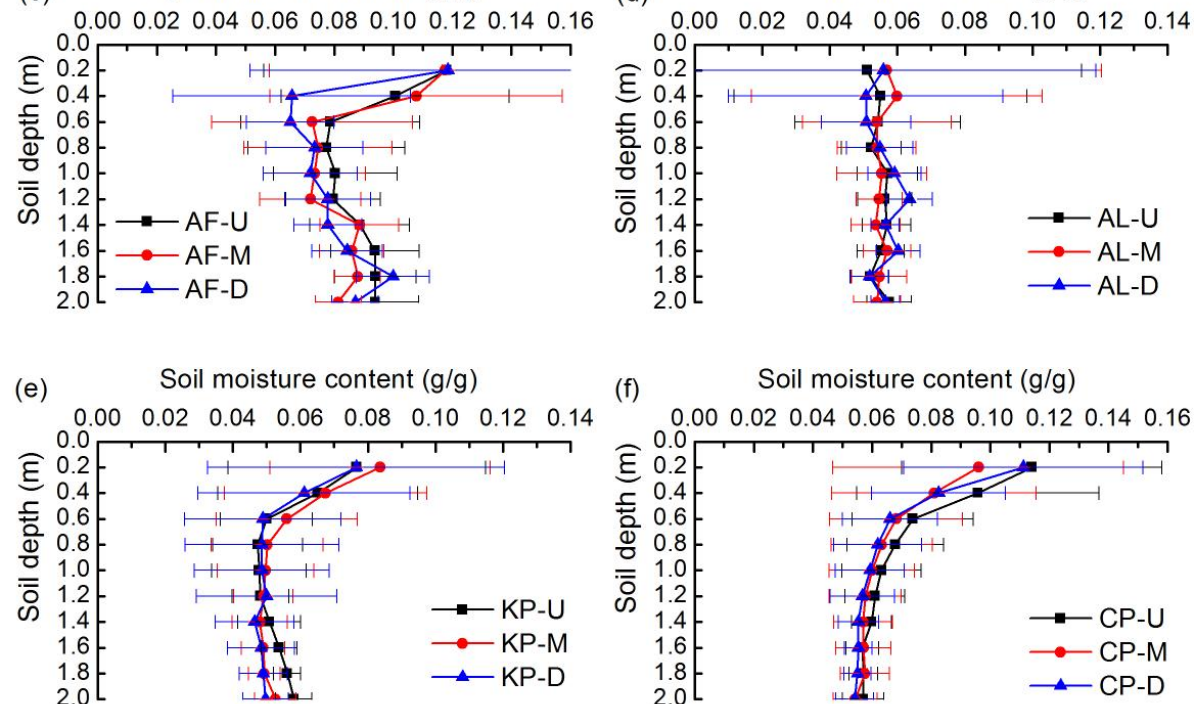

(f) Soil moisture content $(\mathrm{g} / \mathrm{g})$
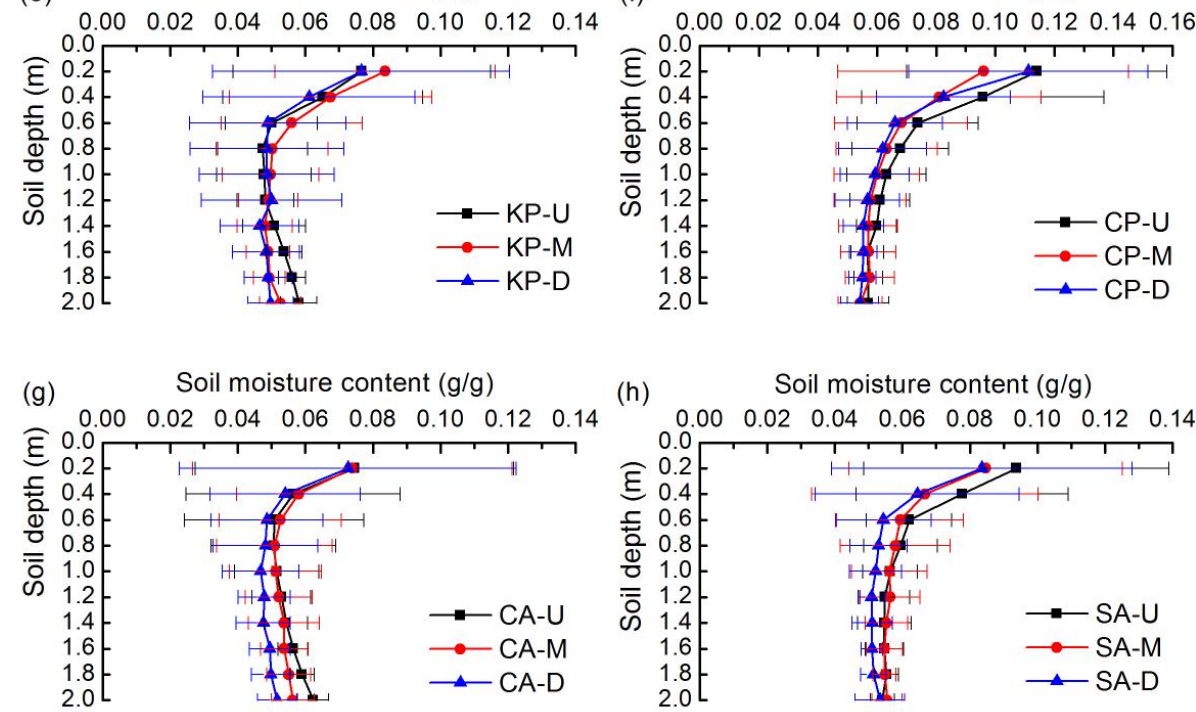

Fig. 2. Comparison of temporal-averaged shallow soil moisture content (SMC) on different slope positions. Note: NG represents native grassland; PO represents farmland planted with potato; AF represents abandoned farmland; AL represents alfalfa; KP represents korshinsk peashrub; CP represents Chinese red pine; CA represents Chinese arborvitae; SA represents Siberian apricot. The number of samples of shallow soil moisture content was 26. The last letter $\mathrm{U}$ refers to upper position, $\mathrm{M}$ to middle position, and $\mathrm{D}$ to downhill position. For example, NG-U, NG-M and NG-D refer to upper position of natural grassland, middle position of natural grassland and downhill position of natural grassland, respectively.

highest SMC was found on the upper positions in the native grassland transect, and then followed by downhill and middle positions. Mean SMC on downhill positions usually had the lowest value in transects with shrub and forest covers (Table 2, Fig. 2). Relatively higher SMC was found in top soil layers in lands with introduced vegetation; however, relative lower values appeared in the deeper layers.

Compared with shallow layers, significant differences in SMC between different slope positions appeared in the deep layers in some transects (Table 2). On native grassland transects, SMC on middle position was significantly lower than that on downhill position. In korshinsk peashrub and Siberian apricot transects, SMC on upper positions was significantly higher than those on the middle and downhill positions. Higher SMC appeared on middle position in Chinese arborvitae transect. However, significant differences were still not found in farmland, alfalfa grasslands, and Chinese red pine transects. The difference in SMC between different 


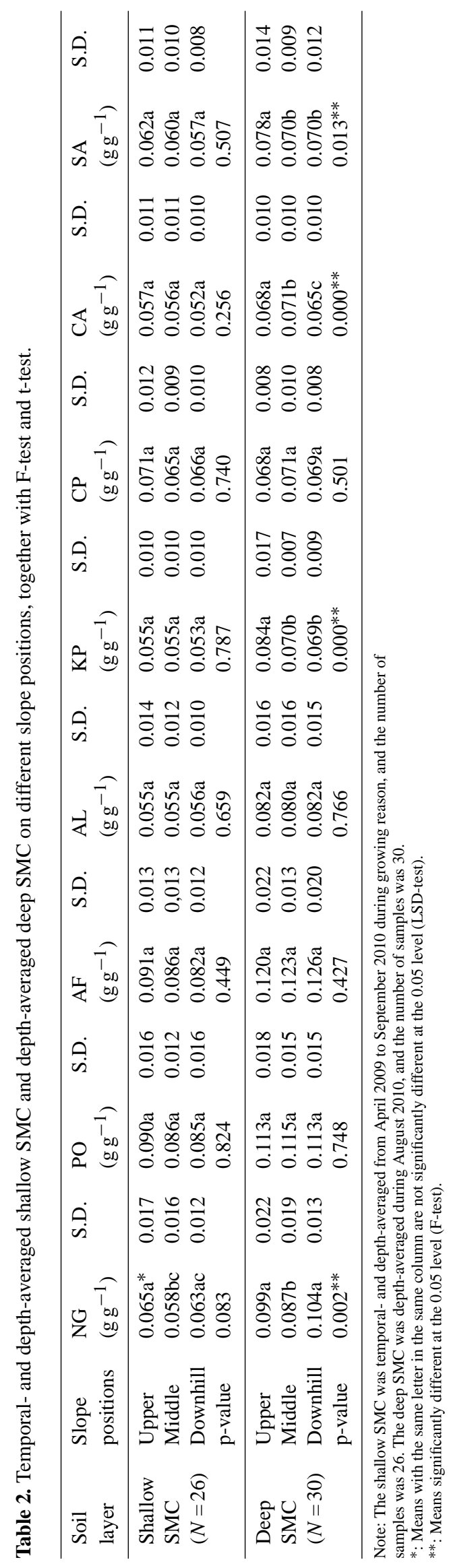


Table 3. Temporal- and depth-averaged shallow SMC and depth-averaged deep SMC on different slope aspects, together with t-test.

\begin{tabular}{|c|c|c|c|c|c|c|c|c|c|c|c|c|c|}
\hline $\begin{array}{l}\text { Soil } \\
\text { layer }\end{array}$ & $\begin{array}{l}\text { Slope } \\
\text { aspect }\end{array}$ & $\begin{array}{l}\mathrm{NG} \\
\left(\mathrm{g} \mathrm{g}^{-1}\right)\end{array}$ & S.D. & $\begin{array}{l}\mathrm{PO} \\
\left(\mathrm{g} \mathrm{g}^{-1}\right)\end{array}$ & S.D. & $\begin{array}{l}\mathrm{AF} \\
\left(\mathrm{g} \mathrm{g}^{-1}\right)\end{array}$ & S.D. & $\begin{array}{l}\mathrm{AL} \\
\left(\mathrm{g} \mathrm{g}^{-1}\right)\end{array}$ & S.D. & $\begin{array}{l}\mathrm{KP} 1 \\
\left(\mathrm{~g} \mathrm{~g}^{-1}\right)\end{array}$ & S.D. & $\begin{array}{l}\mathrm{KP} 2 \\
\left(\mathrm{~g} \mathrm{~g}^{-1}\right)\end{array}$ & S.D. \\
\hline Shallow & $\mathrm{S}$ & $0.067 \mathrm{a}^{*}$ & 0.015 & $0.088 \mathrm{a}$ & 0.013 & 0 & 0.013 & $0.074 a$ & 0.012 & $0.059 \mathrm{a}$ & 0.011 & $0.066 \mathrm{a}$ & 0.011 \\
\hline SMC & Sunny & $0.060 \mathrm{~b}$ & 0.013 & $0.087 a$ & 0.012 & $0.066 \mathrm{~b}$ & 0.011 & $0.064 \mathrm{a}$ & 0.012 & $0.055 \mathrm{a}$ & 0.010 & $0.052 \mathrm{~b}$ & 0.010 \\
\hline$(N=26)$ & p-value & $0.045^{* *}$ & & 0.686 & & $0.010^{* *}$ & & 0.103 & & 0.448 & & $0.024^{* *}$ & \\
\hline D & & $0.101 \mathrm{a}$ & & 0 & & $0.127 \mathrm{a}$ & & $0.076 a$ & 3 & 0 & & $0.068 \mathrm{a}$ & 0.009 \\
\hline SMC & Sunny & $0.102 \mathrm{a}$ & 0.024 & $0.114 a$ & 0.021 & $0.106 \mathrm{~b}$ & 0.024 & $0.080 \mathrm{a}$ & 0.013 & $0.070 \mathrm{a}$ & 0.007 & $0.068 \mathrm{a}$ & 0.009 \\
\hline$(N=30)$ & $\mathrm{p}$ value & $0-828$ & & 0.780 & & $0.000^{* *}$ & & 0.358 & & 0.140 & & 0.871 & \\
\hline
\end{tabular}

Note: The shallow SMC was temporal- and depth-averaged from April 2009 to September 2010 during growing reason, and the number of samples was 26 . The deep SMC was depth-averaged during August 2010, and the number of samples was 30.

*: Means with the same letter in the same column are not significantly different at the 0.05 level (t-test).

**: Means significantly different at the 0.05 level (t-test); KP1 and KP2 are sampling sites on the middle and downhill positions of korshinsk peashrub transect.

slope positions was enlarged along with increasing soil depth in natural grasslands, korshinsk peashrub, Chinese arborvitae and Siberian apricot transects. For example, in Siberian apricot transect, SMC on upper position was $16.2 \%$ and $13.7 \%$ higher, respectively, than that on the middle and downhill positions below the depth of $4.6 \mathrm{~m}$. On the contrary, no significant difference appeared in the depth of 2-4.6 m.

\subsection{Spatial variations of SMC on different slope aspects}

In shallow soil layers, mean SMC on shady slopes was higher than that on sunny slopes in different vegetation covers (Table 3). Furthermore, the difference in SMC between different slope aspects varied with vegetation types. From the comparison of SMC in vertical distribution, SMC on shady slopes usually had higher values than that on sunny slopes (Fig. 5). It indicates that slope aspect was an important factor influencing soil moisture in shallow layers.

However, the comparison of mean value and vertical distribution of deep SMC showed a difference from that in shallow SMC. Generally, no significant difference in SMC was found between shady and sunny sloping lands, except the abandoned farmland (Table 3). This result was also proven by the vertical distribution of SMC in deep layers, no matter what vegetation covers were present (Fig. 6). Results reflected that the slope aspect can only affect SMC in shallow layers, but the influence cannot reach the deep soil layers. Specifically, relatively higher SMC was found on shady slopes in abandoned farmland, rather than on sunny slopes.

\subsection{Spatial variations of SMC in different slope gradients}

Generally, SMC in gentle slopes was much higher than that in steeper slopes in shallow layers (Table 4), although not all the differences were significant. For example, no significant difference was found between Chinese arborvitae forestland in slope gradient of $12^{\circ}$ and $23^{\circ}$; however, Fig. 6d shows that the values on gentle slope were obviously higher than the steeper slope in most layers. On the contrary, the highest mean SMC appeared in steepest slope in natural grassland. The differences in SMC between lands with different slope gradients decreased along with increasing soil depth on vertical distribution (Fig. 6). For example, the difference between alfalfa grassland in $8^{\circ}$ and $13^{\circ}$ at the depth of $0.2 \mathrm{~m}$ was $0.033 \mathrm{~g} \mathrm{~g}^{-1}$, but decreased to $0.014 \mathrm{~g} \mathrm{~g}^{-1}$ at the depth of $1.8 \mathrm{~m}$.

Consistent with shallow soil layers, obvious differences can also be found in deep layers (Table 4, Fig. 7). SMC in gentle slopes was significantly higher than that in steep slopes, especially in deep soil layers. Furthermore, such difference varies with vegetation types. The results reflect that slope gradient can affect SMC both in shallow and deep soil layers. In contrast to vertical distribution characters of shallow soil moisture, the difference in SMC between different slope gradients was enlarged along with increasing soil depth.

\subsection{Statistical analysis for SMC and environmental factors}

Correlation analysis proved that slope position and aspect had no direct influence on deep SMC (Table 5). However, correlation coefficient between slope aspect and shallow SMC was -0.483 , and this indicated slope aspect can influence shallow SMC. This was also proved by CCA in Fig. 8a. Negative relationships between SMC and slope gradient were found in shallow and deep layers (Table 5).

Vegetation type was the dominant environmental variable correlating with the first CCA axis (Fig. 8b), which indicated that significant difference of SMC appeared in lands with different vegetation covers, and vegetation type was the dominant factor influencing SMC. Slope aspect and gradient were also important factors for spatial variation of shallow SMC (Fig. 8a). The experimental sites of eight transects on the CCA ordination biplot are not arranged with slope positions in Fig. 8b. This indicated slope position was not the main affecting factor for spatial variation of deep SMC. However, experiments sites of group 3 on the CCA ordination biplot were changed with slope gradients. These results 
Table 4. Temporal- and depth-averaged shallow SMC and depth-averaged deep SMC in different slope gradients together with F-test and t-test.

\begin{tabular}{|c|c|c|c|c|c|}
\hline $\begin{array}{l}\text { Vegetation } \\
\text { types }\end{array}$ & $\begin{array}{r}\text { Slope } \\
\text { gradient }\left({ }^{\circ}\right)\end{array}$ & $\begin{array}{l}\text { Shallow SMC } \\
\left(\mathrm{g} \mathrm{g}^{-1}, N=26\right)\end{array}$ & S.D. & $\begin{array}{l}\text { Deep SMC } \\
\left(\mathrm{g} \mathrm{g}^{-1}, N=30\right)\end{array}$ & S.D. \\
\hline \multirow[t]{3}{*}{$\mathrm{NG}$} & $9^{\circ}$ & $0.070 \mathrm{a}^{*}$ & 0.015 & $0.101 \mathrm{a}$ & 0.022 \\
\hline & $13^{\circ}$ & $0.066 \mathrm{a}$ & 0.010 & $0.087 \mathrm{~b}$ & 0.013 \\
\hline & $24^{\circ}$ & $0.067 \mathrm{a}$ & 0.011 & $0.080 \mathrm{~b}$ & 0.009 \\
\hline $\mathrm{p}$-value & & 0.388 & & $0.000^{* *}$ & \\
\hline \multirow[t]{3}{*}{$\mathrm{AL}$} & $8^{\circ}$ & $0.077 \mathrm{a}$ & 0.010 & $0.083 \mathrm{a}$ & 0.015 \\
\hline & $13^{\circ}$ & $0.057 \mathrm{~b}$ & 0.014 & $0.082 \mathrm{a}$ & 0.016 \\
\hline & $24^{\circ}$ & $0.060 \mathrm{~b}$ & 0.011 & $0.074 b$ & 0.013 \\
\hline $\mathrm{p}$-value & & $0.000^{* *}$ & & 0.060 & \\
\hline \multirow[t]{2}{*}{$\mathrm{CP}$} & $7^{\circ}$ & $0.071 \mathrm{a}$ & 0.012 & $0.068 \mathrm{a}$ & 0.008 \\
\hline & $23^{\circ}$ & $0.058 \mathrm{~b}$ & 0.010 & $0.065 \mathrm{a}$ & 0.011 \\
\hline p-value & & $0.046^{* *}$ & & 0.165 & \\
\hline \multirow[t]{2}{*}{$\mathrm{CA}$} & $12^{\circ}$ & $0.058 \mathrm{a}$ & 0.012 & $0.078 \mathrm{a}$ & 0.011 \\
\hline & $23^{\circ}$ & $0.057 \mathrm{a}$ & 0.011 & $0.067 \mathrm{~b}$ & 0.007 \\
\hline p-value & & 0.660 & & $0.000^{* *}$ & \\
\hline
\end{tabular}

Note: The shallow SMC was temporal- and depth-averaged from April 2009 to September 2010 during growing reason, and the number of samples was 26. The deep SMC was depth-averaged during August 2010, and the number of samples was 30 .

*: Means with the same letter in the same column are not significantly different at the 0.05 level (LSD-test).

**: Means significantly different at the 0.05 level (F-test).

were consistent with correlation analysis between SMC and different topographical factors.

\section{Discussion}

\subsection{Vertical and temporal variation of SMC in semi-arid Loess Plateau}

Shallow soil moisture was more prone to be affected by vegetation transpiration and soil evaporation (Meerveld and McDonnell, 2006; Seneviratne et al., 2010; Wang et al., 2012). Furthermore, soil moisture at this depth was often intensively affected by plant root systems (Cong et al., 1990; February and Higgins, 2010). The loess soil has a homogeneous texture and the soil is full of capillary pores, which has a strong capacity for evaporation. As a consequence, a relatively stable, low and shallow SMC was always found in this region (Yang and Tian, 2004). For these reasons, SMC in this area was always low in shallow layers. In this study, mean SMC in shallow layers was obviously lower than that in deep layers (Tables 2-4). For the soil evaporation effect on soil moisture to be lessened with the increase in soil depth and the decrease of plant root networks, the SMC increased with soil depth in deeper layers. Previous studies have found that low spatial and temporal variations usually appeared in lower SMC, and increased when SMC became higher (Ibrahim and Huggins, 2011; Western and Blöschl, 1999). This phenomenon can explain why the differences of shallow SMC were lower than deep SMC. Because SMC in shallow layers was always low,
Table 5. Correlation analysis of SMC and topographical factors.

\begin{tabular}{lrr}
\hline & $\begin{array}{r}\text { shallow } \\
\text { SMC }\end{array}$ & $\begin{array}{r}\text { deep } \\
\text { SMC }\end{array}$ \\
\hline $\begin{array}{l}\text { Slope position } \\
(N=24)\end{array}$ & -0.151 & -0.089 \\
p-value & 0.481 & 0.681 \\
\hline $\begin{array}{l}\text { Slope aspect } \\
(N=12)\end{array}$ & -0.483 & 0 \\
p-value & 0.112 & 1 \\
\hline $\begin{array}{l}\text { Slope gradient } \\
(N=10) \\
\text { p-value }\end{array}$ & -0.604 & -0.481 \\
\hline
\end{tabular}

Note: correlation analyses between SMC and slope position and slope aspect were using Spearman analysis, and correlation analysis between SMC and slope gradient was using Pearson analysis.

significant differences in shallow SMC were difficult to be found between different environmental variables. However, a significant difference appeared in deep layers due to the increasing SMC.

In the semi-arid Loess Plateau, SMC varies inter-annually at the depth of $0 \mathrm{~m}-2 \mathrm{~m}$, depending on annual precipitation. However, due to the thickness of loess covering the Loess Plateau, vertical distribution and temporal variations of SMC are different from other semi-arid areas. Wang et al. (2009) 
found no significant inter-annual changes in the depth below $2 \mathrm{~m}$ based on six years of observations in the loess hilly region. Chen et al. (2008b) also found that the depth of soil affected by the rainfall was only $0-2 \mathrm{~m}$ in the drought years by natural and simulated rainfall experiments. In fact, annual rainfall infiltration depth can hardly reach $1 \mathrm{~m}$ soil layer in the study area, according to field soil moisture observations (Yang et al., 2011). In this area, the S.D. of SMC on each experimental site was relatively high at $0-1 \mathrm{~m}$, but the value became lower at a depth of $1 \mathrm{~m}$ during observations from 2009 to 2010 (Figs. 2, 4 and 6). This result indicated that SMC only varied with rainfall in shallow soil layers, but remained stable in deep layers for several years. In these cases, therefore, we used the temporal-averaged shallow soil moisture content data obtained from April to October to provide accurate characterizations of temporal changes in SMC and to represent SMC conditions in shallow layers. Because the deep SMC was relatively stable during these years, the oneyear of deep SMC data obtained in August is sufficient to reflect the stable soil moisture conditions in the deep profiles.

\subsection{Different dynamic rules between deep and shallow SMC}

Topography factors, such as upslope contributing areas, aspects, and gradients, are commonly considered important factors for the spatiotemporal soil moisture variations (Venkatesh et al., 2011; Western et al., 1999, 2004). The general spatial pattern of SMC on watershed-scale is increased value along with surface flow direction from the top to the bottom of a hill slope. The sunny slope usually gets more solar radiation than the shady slope, and this can lead to more soil moisture transpiration. Thus, SMC in upper soil layers on a sunny slope is usually lower than that on a shady slope (Galicia et al., 1999). Furthermore, a steep slope usually has a lower SMC than a gentle slope. Spatial distributions of SMC in these patterns have been proven by many previous studies (Francis et al., 1986; Legates et al., 2011; Western and Blöschl, 1999) and models (Cantón et al., 2004; Western et al., 1999). In loess hilly region, spatial variations of SMC in $0 \sim 0.7 \mathrm{~m}$ affected by the topographic factors also correspond to this spatial pattern (Qiu et al., 2001, 2010). Similar patterns were captured in deep SMC. For example, $\mathrm{He}$ et al. (2003) held the view that slope gradient, aspect, and position could affect deep SMC. Wang et al. (2008) and Zhao et al. (2007) found that SMC in a shady slope was higher than that in a sunny slope in forestlands and grasslands. In this study, the deep SMC on the middle position was lower than that on the downhill position in native grasslands (Fig. 3a), SMC on gentle slopes lower than that on steep slopes (Fig. 7a), and SMC on shady slopes higher than that on sunny slopes (Fig. 5a). The result reflected that the spatial pattern of deep SMC with local native vegetation was corresponding to the spatial distribution patterns.
However, the spatial variations of deep SMC in introduced vegetation were different than those in native plants. In this study, measured data and statistical analysis provided evidence that topographic factors such as slope aspects can only affect shallow soil layers to a certain extent (Table 5, Fig. 4), but they cannot reach deep soil layers (Fig. 5). In CCA ordination biplot, experimental sites in sunny and shady slopes are separated clearly in Fig. 8a. Furthermore, experimental sites of eight transects are also arranged along with the direction of slope position in CCA ordination biplot. In comparison with shallow SMC, slope position and aspect cannot be identified as an influencing factor on deep SMC by correlation analysis and CCA (Table 5, Fig. 8b). The results reflect that the dynamics of deep SMC were different with shallow SMC under the influence of slope position and aspect. Comparison of SMC in gentle and steep slopes and correlation analysis between slope gradient and SMC indicated that a lower gradient was related to a higher SMC (Table 5, Figs. 6-7). Slope gradient was also indicated as one of main environmental variables correlating with the first CCA axis. Experimental sites are clearly arranged along with the direction of slope gradient in Fig. 8b. This result was consistent with previous findings that slope gradient and SMC had a negative relationship in the semi-arid regions (Cantón et al., 2004; Gómez-Plaza et al., 2001; Qiu et al., 2001). It thus can explain why deep SMC on upper positions of native grasslands transect was higher than on other positions. The slope gradient on upper position was $9^{\circ}$, and slope gradients on the middle and downhill positions were $30^{\circ}$ and $32^{\circ}$, respectively. Thus, the lower the slope gradient on upper position, the higher the SMC will be. Slope gradient as an important topographic factor in the loess hilly region can affect SMC not only in shallow layers but also in deep layers.

\subsection{Relations between plant growth and deep SMC variation under introduced vegetation covers}

Vegetation can have significant influence on SMC (Peel, 2009; Schymanski et al., 2009; Wang et al., 2012). In this study, experimental sites in same vegetation were clearly separated from others along with the direction of vegetation type in CCA of shallow SMC. It indicated that vegetation type is a significant influencing factor on shallow SMC. In the Loess Plateau, dense vegetation plantation with high productivity consumes too much water stored in deep layers. It was the major possible reason for the severe soil moisture deficit in deep layers. For example, using the WinEPIC model, Li et al. (2008) simulated the changes in SMC and productivity of black locust (Robinia pseudoacacia) forestlands and found that the higher the planting density, the faster the decrease of deep SMC. In the semi-arid loess hilly regions, introduced vegetation with high planting density not only drastically decreased deep SMC, but also changed the dynamic rules of SMC in shallow and deep layers. In this study, taking Siberian apricot transect as an example, deep 

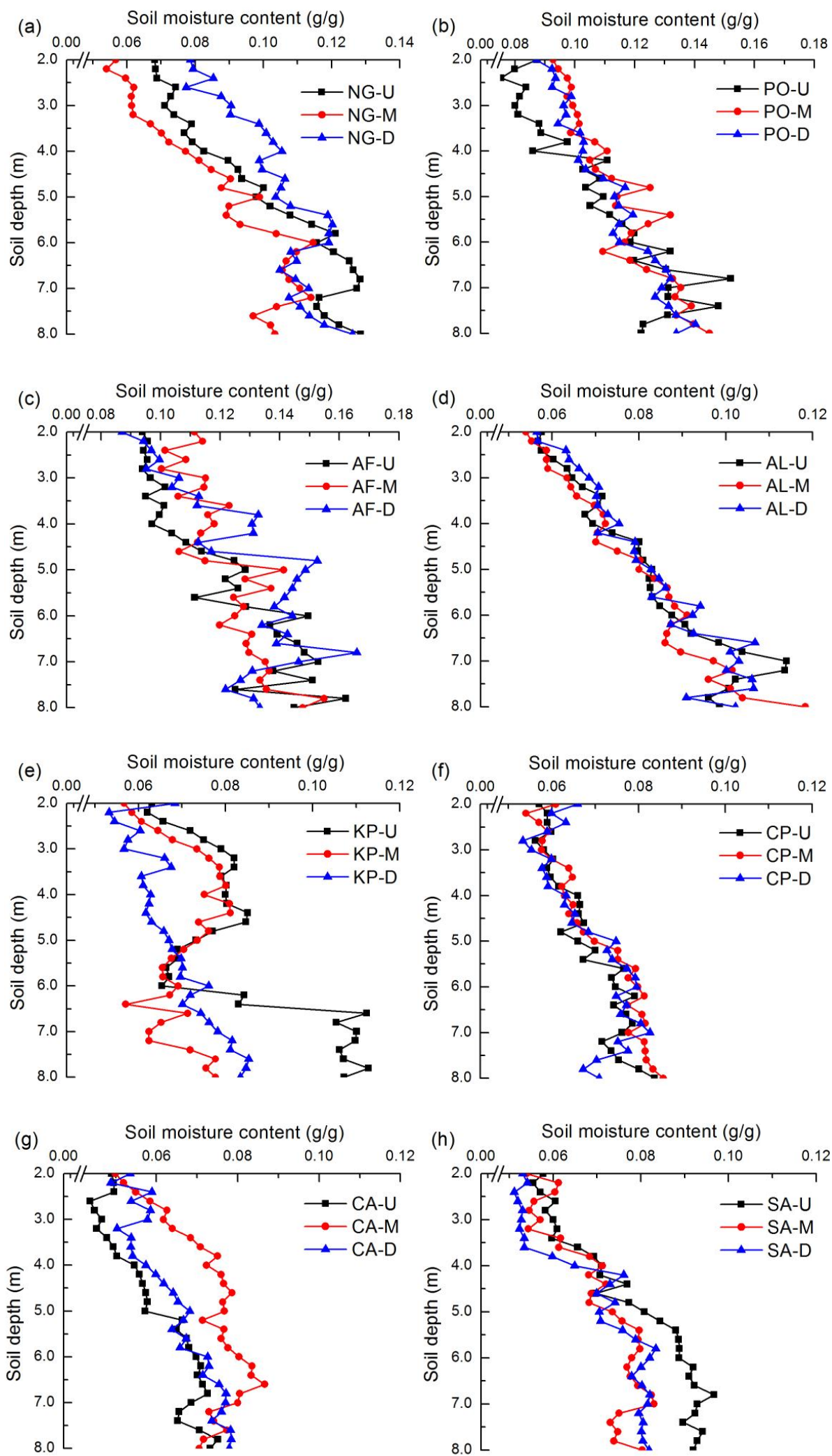

Fig. 3. Comparison of deep soil moisture content (SMC) on different slope positions. Note: NG represents native grassland; PO represents farmland planted with potato; AF represents abandoned farmland; AL represents alfalfa; KP represents korshinsk peashrub; CP represents Chinese red pine; CA represents Chinese arborvitae; SA represents Siberian apricot. The last letter U refers to upper position, M to middle position and D to downhill position. For example, NG-U, NG-M and NG-D refer to upper position of natural grassland, middle position of natural grassland and downhill position of natural grassland, respectively. 

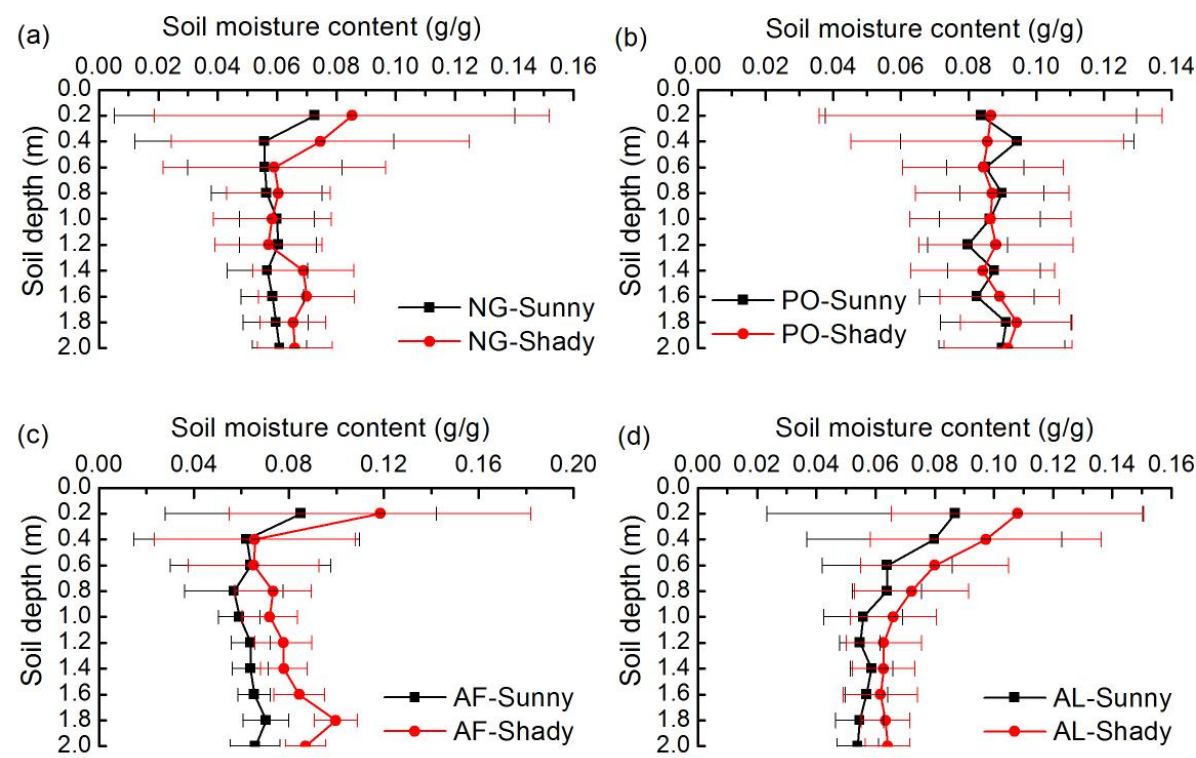

(d) Soil moisture content $(\mathrm{g} / \mathrm{g})$
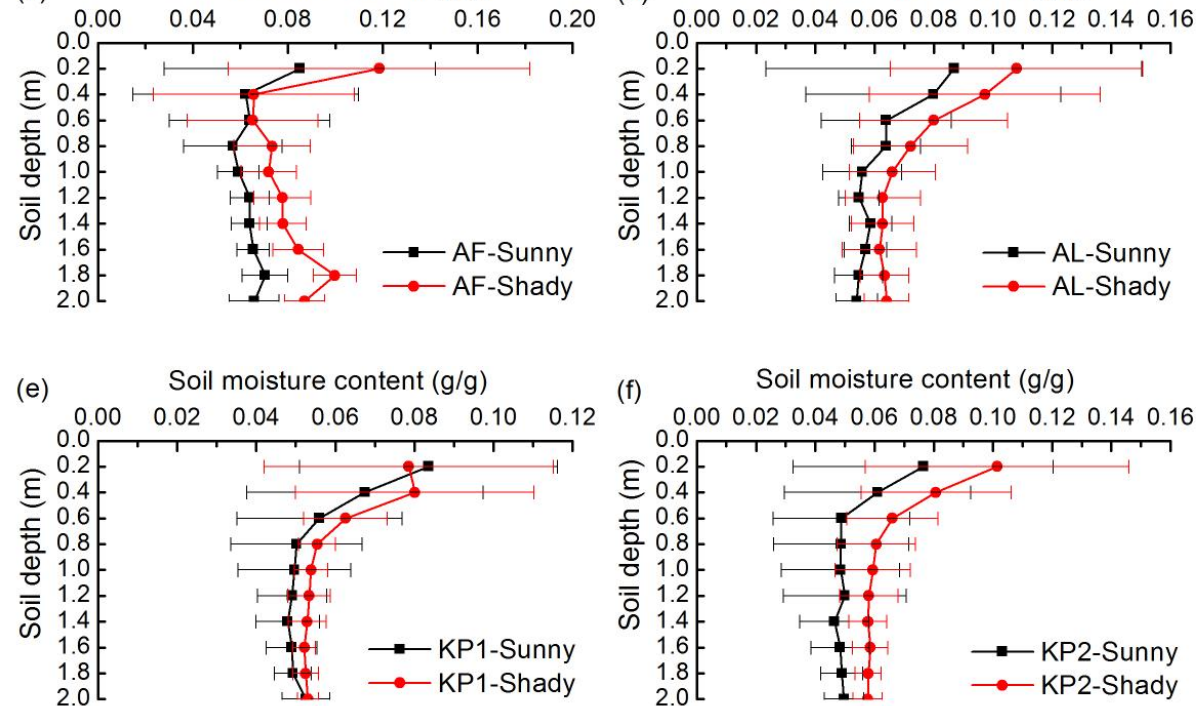

Fig. 4. Comparison of temporal-averaged shallow soil moisture content (SMC) on different slope aspects. Note: NG represents native grassland; PO represents farmland planted with potato; AF represents abandoned farmland; AL represents alfalfa; KP represents korshinsk peashrub. The number of samples of shallow soil moisture content was 26 . Sunny refers to sunny slope and shady refers to shady slope. For example, NG-Shady refers to native grassland on shady slope, and NG-Sunny refers to native grassland on sunny slope.

SMC on upper positions was higher than that on middle and downhill positions, and plant density may be the main reason. Siberian apricot density was 900 plant/ha on upper positions. Although the same planting density of Siberian apricot appeared on middle and downhill positions, korshinsk peashrub with a planting density of 1670 plant/ha was also planted with Siberian apricot on these two positions. Therefore, the total density of introduced vegetation on middle and downhill positions was much higher than that on upper position. Thus, high planting density led to lower deep SMC on these positions (Figs. $2 \mathrm{~h}$ and $3 \mathrm{~h}$ ). In the Chinese arborvitae transect, planting density on the upper and downhill positions was the same (2600 plant/ha), while the mean height of Chinese arborvitae on the upper and downhill positions was $4.18 \mathrm{~m}$ and $3.65 \mathrm{~m}$, respectively. The Chinese arborvitae plants on the middle position had been cut in 1998, and now the planting density is 1300 plant/ha, and their mean height was $3.38 \mathrm{~m}$. The lower planting density on the middle position led to higher deep SMC (Fig. 3g).
In semi-arid regions, more soil moisture evaporation usually appears on upper positions as they suffer more solar radiation and wind that affect plant growth. According to local field investigations, the mean height of korshinsk peashrub plants on the upper position was $1.02 \mathrm{~m}$, but the mean heights on the middle and downhill positions were $1.28 \mathrm{~m}$ and $1.23 \mathrm{~m}$, respectively. Owing to the developed root system, poor growth of korshinsk peashrub on upper position will lead to less soil moisture consumption, especially for deep SMC. This could explain why deep SMC on upper position was significantly higher than other positions (Table 2 , Fig. 2e). In Chinese red pine transect, the mean height of pine trees in the downhill position was $4.90 \mathrm{~m}$ and mean $\mathrm{DBH}$ was $8.1 \mathrm{~cm}$. In contrast, mean heights of pine trees in upper and middle positions were $4.55 \mathrm{~m}$ and $4.48 \mathrm{~m}$, and mean DBH was $7.4 \mathrm{~cm}$ and $6.9 \mathrm{~cm}$, respectively. Better growing conditions of pine trees on a downhill position were associated with a lower deep SMC. Alfalfa was also found to have deep root systems, which could drastically consume deep soil moisture (Wang et al., 2010b). In this study, the 

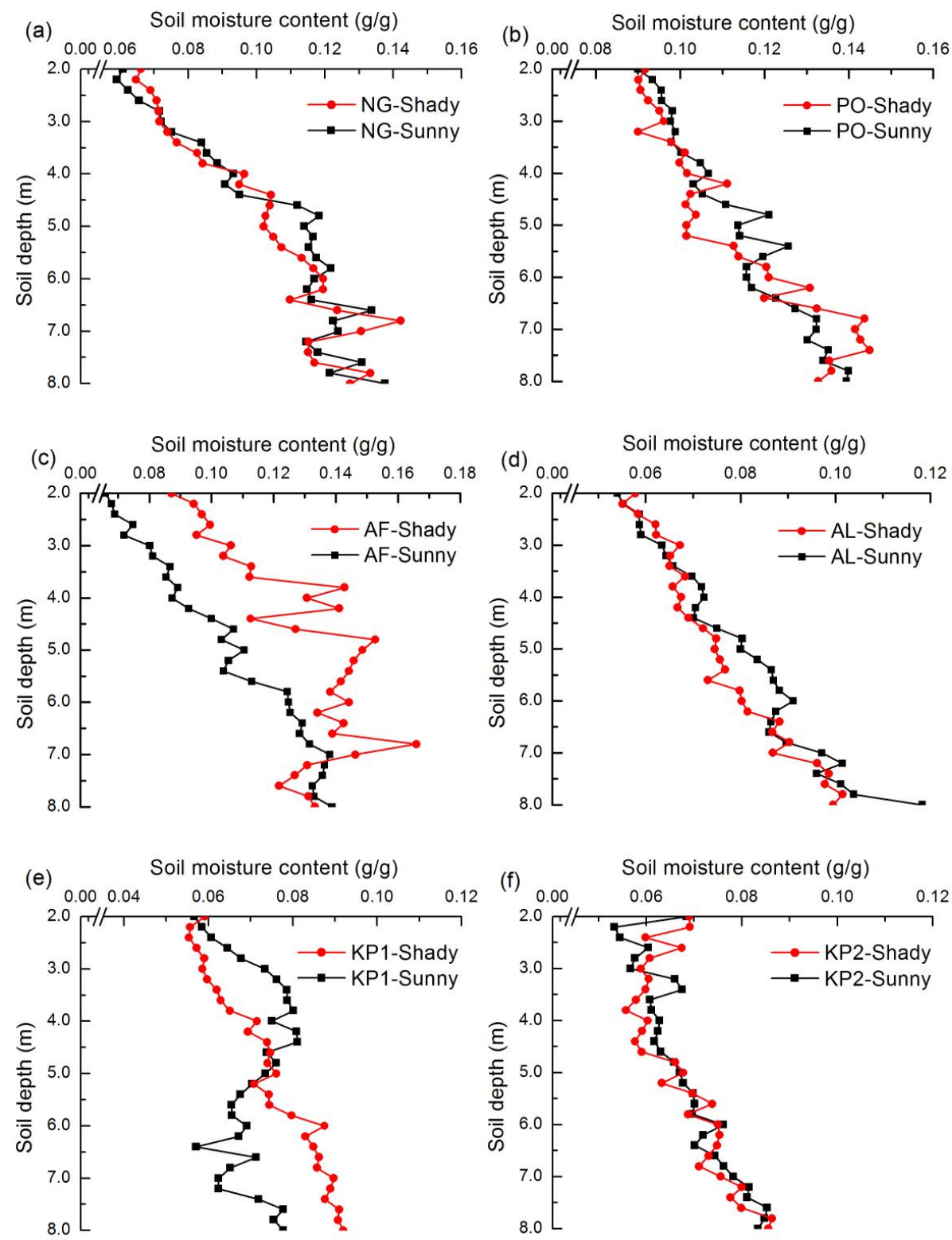

Fig. 5. Comparison of deep soil moisture content (SMC) on different slope aspects. Note: NG represents native grassland; PO represents farmland planted with potato; AF represents abandoned farmland; AL represents alfalfa; KP represents korshinsk peashrub. Sunny and shady refer to sunny slope and shady slope, respectively. For example, NG-Shady refers to native grassland on shady slope, and NG-Sunny refers to native grassland on sunny slope.

fresh weights of alfalfa on the upper and downhill positions of alfalfa transect were $246.3 \mathrm{~g} \mathrm{~m}^{-2}$ and $248.1 \mathrm{~g} \mathrm{~m}^{-2}$, respectively. In contrast, the fresh weight of alfalfa on the middle position reached $314.0 \mathrm{~g} \mathrm{~m}^{-2}$. This high biomass of alfalfa makes the SMC on the middle position lower than that on other positions.

Based on this discussion, introduced vegetation types were noted that can alter the contributions of topography to the specific soil moisture dynamics. Otherwise, the effects of introduced vegetation on the dynamics of soil moisture were not only limited to shallow soil layers, but also to deep layers.
In fact, the plant growing conditions can be considered the main factor affecting the spatial variations of deep SMC. In practice, vegetation restoration with alien species in the semiarid environments should be strongly based on soil moisture conditions. On the other hand, soil moisture data observed in shallow layers are insufficient in evaluating soil moisture conditions for the purpose of vegetation restoration in the semi-arid areas. More attention, however, should be paid to available soil water sources in deep layers. Since the dynamic role of topographic factors on soil moisture has been changed by introduced vegetation, and targeting for a big success of 

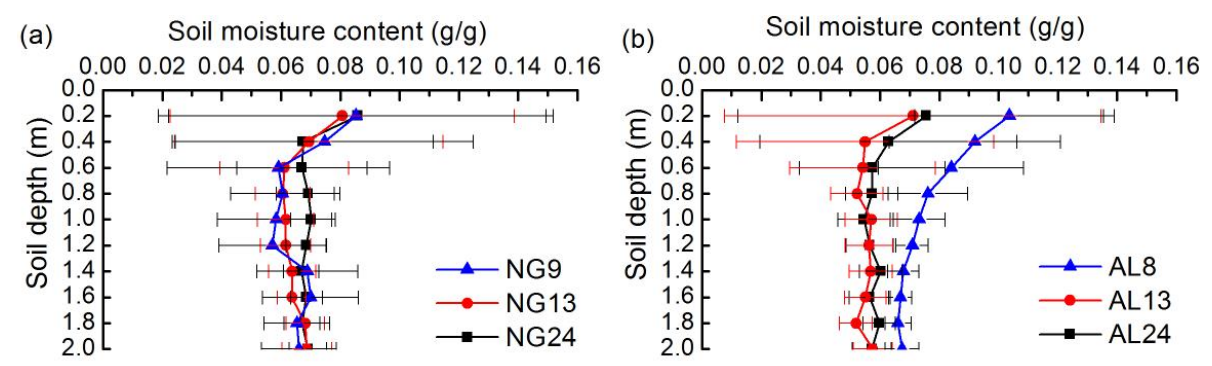

(c) Soil moisture content $(\mathrm{g} / \mathrm{g})$

(d) Soil moisture content $(\mathrm{g} / \mathrm{g})$
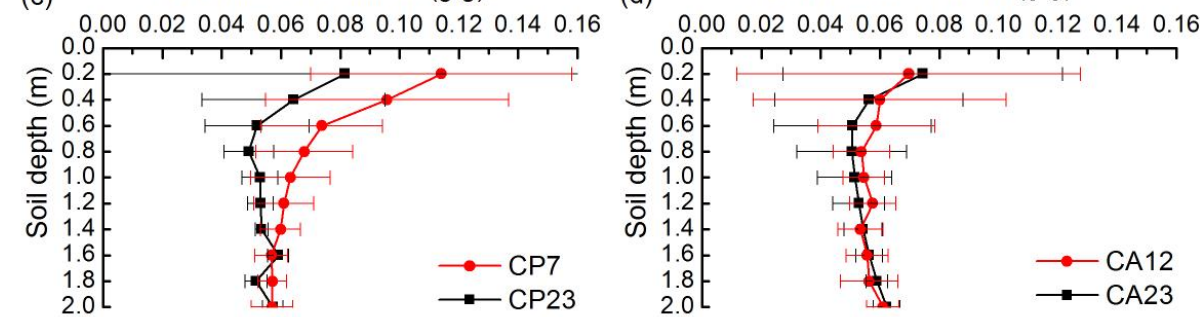

Fig. 6. Comparison of temporal-averaged shallow soil moisture content (SMC) in different slope gradients. Note: NG represents native grassland; AL represents alfalfa; CP represents Chinese red pine; CA represents Chinese arborvitae. The number of samples of shallow soil moisture content was 26 . The last number refers to slope gradient. For example, NG9 refers to native grassland with slope gradient of $9^{\circ}$, NG13 to natural grassland with slope gradient $13^{\circ}, \mathrm{NG} 24^{\circ}$ to natural grassland with slope gradient $24^{\circ}$.
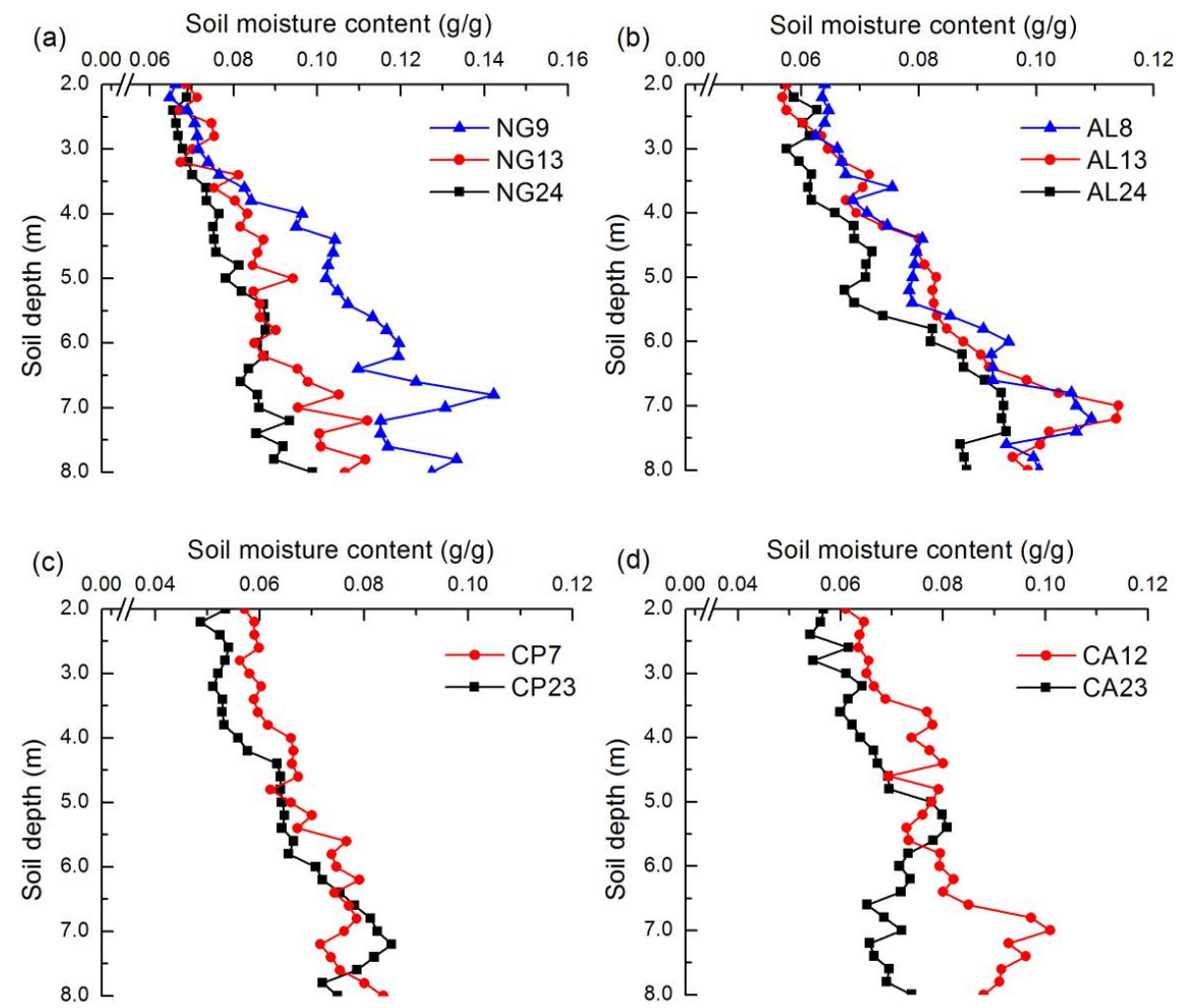

Fig. 7. Comparison of deep soil moisture content (SMC) in different slope gradients. Note: NG represents native grassland; AL represents alfalfa; CP represents Chinese red pine; CA represents Chinese arborvitae. The last number refers to slope gradient. For example, NG9 refers to native grassland with slope gradient of $9^{\circ}$, NG13 to natural grassland with slope gradient $13^{\circ}$, and NG24 to natural grassland with slope gradient $24^{\circ}$. 

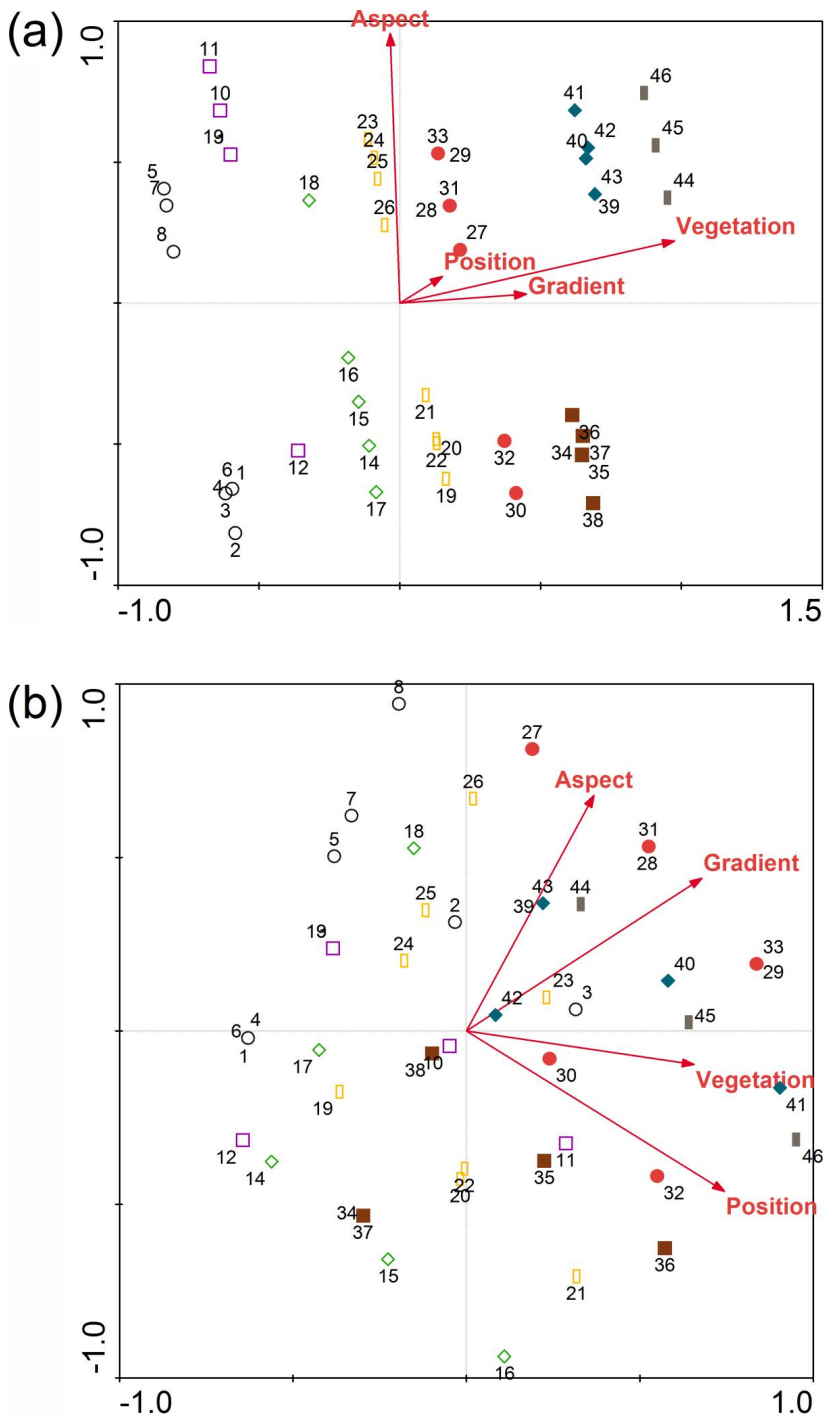

Fig. 8. Canonical correspondence analysis (CCA) ordination biplot showing the relationship between (a) shallow soil moisture content, (b) deep soil moisture content and environmental factors.

eco-construction projects, detailed locations and densities of plants at watershed-scales should be evaluated scientifically according to local soil moisture viability.

\section{Conclusions}

Based on the comparison between soil moisture dynamics in shallow and deep layers, the results indicated that topographic factors such as slope position and aspect only affect SMC in shallow layers, and there is no direct influence on deep soil moisture in introduced vegetations. Slope gradient, on the other hand, has a significant influence on both shallow and deep SMC. Due to the role of vegetation plantation and restoration on soil moisture, the dynamic role of topographic factors on SMC was different between deep and shallow layers. The growing conditions of planted vegetation have a negative relationship with deep SMC, which is considered as the main factor for spatial variations of deep SMC. In practice, therefore, vegetation restoration in semiarid environments should be strongly based on soil moisture conditions. Moreover, in order to ensure the success of ecoconstruction projects, the detailed locations and densities of plants on a watershed-scale should be taken into consideration seriously.

Acknowledgements. This study was supported by the National Natural Science Foundation of China (40925003, 41071122, and 31160099). We thank Lixin Wang and three anonymous reviewers for their constructive comments and suggestions.

Edited by: L. Wang

\section{References}

Cantón, Y., Solé-Benet, A., and Domingo, F.: Temporal and spatial patterns of soil moisture in semiarid badlands of SE Spain, J. Hydrol., 285, 199-214, 2004.

Cao, S., Chen, L., and Yu, X.: Impact of China's Grain for Green Project on the landscape of vulnerable arid and semi-arid agricultural regions: a case study in northern Shaanxi Province, J. Appl. Ecol., 46, 536-543, 2009.

Chazdon, R. L.: Beyond deforestation: restoring forests and ecosystem services on degraded lands, Science, 320, 1458-1460, 2008.

Chen, H., Shao, M., and Li, Y.: Soil desiccation in the Loess Plateau of China, Geoderma, 143, 91-100, 2008 a.

Chen, H., Shao, M., and Li, Y.: The characteristics of soil water cycle and water balance on steep grassland under natural and simulated rainfall conditions in the Loess Plateau of China, J. Hydrol., 360, 242-251, 2008b.

Chen, L., Huang, Z., Gong, J., Fu, B., and Huang, Y.: The effect of land cover/vegetation on soil water dynamic in the hilly area of the loess plateau, china, Catena, 70, 200-208, 2007a.

Chen, L., Wei, W., Fu, B., and Lü, Y.: Soil and water conservation on the loess plateau in China: review and perspective, Prog. Phys. Geogr., 31, 389-403, 2007b.

Chen, L., Wang, J., Wei, W., Fu, B., and Wu, D.: Effects of landscape restoration on soil water storage and water use in the Loess Plateau Region, China, Forest Ecol. Manage., 259, 1291-1298, 2010.

Cong, X., Liang, Y., and Li, D.: Root characteristics of Hippophae rhamnoides and dynamic of soil water in semi-arid on Loess Plateau, Bull. Soil Water Conserv., 10, 98-103, 1990.

Engelbrecht, B. M. J., Comita, L. S., Condit, R., Kursar, T. A., Tyree, M. T., Turner, B. L., and Hubbell, S. P.: Drought sensitivity shapes species distribution patterns in tropical forests, Nature, 447, 80-82, 2007.

Favreau, G., Cappelaere, B., Massuel, S., Leblanc, M., Boucher, M., Boulain, N., and Leduc, C.: Land clearing, Climate variability, and water resources increase in semiarid southwest Niger: A review, Water Resour. Res., 45, W00A16, doi:10.1029/2007WR006785, 2009. 
February, E. C. and Higgins, S. I.: The distribution of tree and grass roots in savannas in relation to soil nitrogen and water, S. Afr. J. Bot., 76, 517-523, 2010.

Fitzjohn, C., Ternan, J. L., and Williams, A. G.: Soil moisture variability in a semi-arid gully catchment: implications for runoff and erosion control, Catena, 32, 55-70, 1998.

Francis, C. F., Thornes, J. B., Diaz, A. R., Bermudez, F. L., and Fisher, G. C.: Topographic control of soil moisture, vegetation cover and land degradation in a moisture stressed mediterranean environment, Catena, 13, 211-225, 1986.

Fu, B., Wang, J., Chen, L. and Qiu, Y.: The effects of land use on soil moisture variation in the Danangou catchment of the Loess Plateau, China, Catena, 54, 197-213, 2003.

Galicia, L., Lopez-Blanco, J., Zarco-Arista, A. E., Filips, V., and Garcia-Oliva, F.: The relationship between solar radiation interception and soil water content in a tropical deciduous forest in Mexico, Catena, 36, 153-164, 1999.

Gómez-Plaza, A., Alvarez-Rogel, J., Albaladejo, J., and Castillo, V. M.: Spatial patterns and temporal stability of soil moisture across a range of scales in a semi-arid environment, Hydrol. Process., 14, 1261-1277, 2000.

Gómez-Plaza, A., Martínez-Mena, M., Albaladejo, J., and Castillo, V. M.: Factors regulating spatial distribution of soil water content in small semiarid catchments, J. Hydrol., 253, 211-226, 2001.

He, F., Huang, M., and Dang, Y.: Distribution characteristic of dried soil layer in Wangdonggou watershed in gully region of Loess Plateau, J. Nat. Resour., 18, 30-36, 2003.

Hebrard, O., Voltz, M., Andrieux, P., and Moussa, R.: Spatiotemporal distribution of soil surface moisture in a heterogeneously farmed Mediterranean catchment, J. Hydrol., 329, 110$121,2006$.

Ibrahim, H. M. and Huggins, D. R.: Spatio-temporal patterns of soil water storage under dryland agriculture at the watershed scale, J. Hydrol., 404, 186-197, 2011.

Legates, D. R., Mahmood, R., Levia, D. F., Deliberty, T. L., Quiring, S. M., Houser, C., and Nelson, F. E.: Soil moisture: A central and unifying theme in physical geography, Prog. Phys. Geogr., 35, 65-86, 2011.

Li, J., Wang, X., Shao, M., Zhao, Y., and Li, X.: Simulation of water productivity and soil desiccation effects of different planting density black locust forestlands on the Loess Plateau, Acta Ecol. Sin., 28, 3125-3142, 2008.

Liu, J., Li, S., Ouyang, Z., Tam, C., and Chen, X.: Ecological and socioeconomic effects of China's policies for ecosystem services. Proceeding of the National Academy of Sciences of the United States of America, 105, 9477-9482, 2008.

Liu, W., Zhang, X., Dang, T., Ouyang, Z., Li, Z., Wang, J., Wang, R., and Gao, C.: Soil water dynamics and deep soil recharge in a record wet year in the southern Loess Plateau of China, Agr. Water Manage., 97, 1133-1138, 2010.

Liu, Y., Li, S., Chen, F., Yang, S., and Chen, X.: Soil water dynamics and water use efficiency in spring maize fields subjected to different water management practices on the Loess Plateau, China, Agr. Water Manage., 97, 769-775, 2010.

Meerveld, H. J. T. and McDonnell, J. J.: On the interrelations between topography, soil depth, soil moisture, transpiration rates and species distribution at the hillslope scale, Adv. Water Resour., 29, 293-310, 2006.
Mu, X., Xu, X., Wang, W., Wen, Z., and Du, F.: Impact of artificial forest on soil moisture of the deep soil layer on Loess Plateau, Acta Pedol. Sin., 40, 210-217, 2003.

Peel, M. C.: Hydrology: catchment vegetation and runoff, Prog. Phys. Geogr., 33, 837-844, 2009.

Qiu, Y., Fu, B., Wang, J. and Chen, L.: Spatial variability of soil moisture content and its relation to environmental indices in a semi-arid gully catchment of the Loess Plateau, China, J. Arid Environ., 49, 723-750, 2001.

Qiu, Y., Fu, B., Wang, J., and Chen, L.: Spatiotemporal prediction of soil moisture content using multiple-linear regression in a small catchment of the Loess Plateau, China, Catena, 54, 173-195, 2003.

Qiu, Y., Fu, B., Wang, J., Chen, L., Meng, Q., and Zhang, Y.: Spatial prediction of soil moisture content using multiple-linear regressions in a gully catchment of the Loess Platau, China, J. Arid Environ., 74, 208-220, 2010.

Schymanski, S. J., Sivapalan, M., Roderick, M. L., Hutley, L. B., and Beringer, J.: An optimality-based model of the dynamic feedbacks between natural vegetation and the water balance, Water Resour. Res., 45, W01412, doi:10.1029/2008WR006841, 2009.

Seneviratne, S. I., Corti, T., Davin, E. L., Hirschi, M., Jaeger, E. B., Lehner, I., Orlowsky, B., and Teuling, A. J.: Investigating soil moisture-climate interactions in a changing climate: A review, Earth-Sci. Rev., 99, 125-161, 2010.

Shi, Z. H., Fang, N. F., Wu, F. Z., Wang, L., Yue, B. J., and Wu, G. L.: Soil erosion processes and sediment sorting associated with transport mechanisms on steep slopes, J. Hydrol., 454-455, 123130, 2012.

Venkatesh, B., Lakshman, N., Purandara, B. K., and Reddy, V. B.: Analysis of observed soil moisture patterns under different land covers in Western Ghats, India, J. Hydrol., 397, 281-294, 2011.

Vivoni, E. R., Rinehart, A. J., Méndez-Barroso, L. A., Aragón, C. A., Bisht, G., Cardenas, M. B., Engle, E., Forman, B. A., Frisbee, M. D., Gutiérrez-Jurado, H. A., Hong, S., Mahmood, T. H., Tai, K., and Wyckoff, R. L.: Vegetation controls on soil moisture distribution in the Valles Caldera, New Mexico, during the North American monsoon, Ecohydrology, 1, 225-238, 2008.

Wang, G., Innes, J. L., Lei, J., Dai, S., and Wu, S. W.: China's forestry reforms, Science, 318, 1556-1557, 2007.

Wang, L., Wang, Q., Wei, S., Shao, M., and Li, Y.: Soil desiccation for loess soils on natural and regrown areas, Forest Ecol. Manage., 255, 2467-2477, 2008.

Wang, L., Wei, S., Horton, R., and Shao, M.: Effects of vegetation and slope aspect on water budget in the hill and gully region of the Loess Plateau of China, Catena, 87, 90-100, 2011.

Wang, L., D’Odorico, P., Evans, J. P., Eldridge, D. J., McCabe, M. F., Caylor, K. K., and King, E. G.: Dryland ecohydrology and climate change: critical issues and technical advances, Hydrol. Earth Syst. Sci., 16, 2585-2603, doi:10.5194/hess-16-25852012, 2012.

Wang, Y., Shao, M., and Liu, Z.: Large-scale spatial variability of dried soil layers and related factors across the entire Loess Plateau of China, Geoderma, 159, 99-108, 2010a.

Wang, Y., Shao, M., and Shao, H.: A preliminary investigation of the dynamic characteristics of dried soil layers on the Loess Plateau of China, J. Hydrol., 381, 9-17, 2010 b. 
Wang, Y., Shao, M., Zhu, Y., and Liu, Z.: Impacts of land use and plant characteristics on dried soil layers in different climatic regions on the Loess Plateau of China, Agr. Forest Meteorol., 151, 437-448, 2011.

Wang, Z., Liu, B., and Zhang, Y.: Soil moisture of different vegetation types on the Loess Plateau, J. Geogr. Sci., 19, 707-718, 2009.

Western, A. W. and Blöschl, G.: On the spatial scaling of soil moisture, J. Hydrol., 217, 203-224, 1999.

Western, A. W., Grayson, R. B., Blöschl, G., Willgoose, G. R., and McMahon, T. A.: Observed spatial organization of soil moisture and its relation to terrain indices, Water Resour. Res., 35, 797$810,1999$.

Western, A. W., Zhou, S. L., Grayson, R. B., McMahon, T. A., Blöschl, G., and Wilson, D. J.: Spatial correlation of soil moisture in small catchments and its relationship to dominant spatial hydrological processes, J. Hydrol., 286, 113-114, 2004.
Yang, K., Liu, G., Wu, F., and Sun, B.: Hydrological and environmental responses to comprehensive control of soil loss in a typical watershed of hill and gully region of the Loess Plateau, Acta Ecol. Sin., 28, 2042-2051, 2008.

Yang, L., Wei, W., Mo, B., and Chen, L.: Soil water deficit under different artificial vegetation restoration in the semi-arid hilly region of the Loess Plateau, Acta Ecol. Sin., 31, 3060-3068, 2011.

Yang, W. and Tian, J.: Essential exploration of soil aridization in Loess Plateau, Acta Pedol. Sin., 41, 1-6, 2004.

Zhao, J., Du, J., and Chen, B.: Dried earth layers of artificial forestland in the Loess Plateau of Shaanxi Province, J. Geogr. Sci., 17, 114-126, 2007.

Zhu, Y. and Shao, M.: Variability and pattern of surface moisture on a small-scale hillslope in Liudaogou catchment on the northern Loess Plateau of China, Geoderma, 147, 185-191, 2008. 